\title{
Ações de equipes gestoras para o ensino de matemática nos anos iniciais
}

\author{
Actions of management teams for the teaching of mathematics in the early years
}

Acciones del equipo directivo para la enseñanza de las matemáticas en los primeros años

\begin{abstract}
Antonio Carlos Arantes - Universidade Federal de São Carlos | Departamento | Sorocaba | SP | Brasil. E-mail: proftuco@hotmail.com | (1) orciD

Renata Prenstteter Gama - Universidade Federal de São Carlos | Centro de Educação e Ciências Humanas, Departamento de Metodologia de Ensino | São Carlos | SP | Brasil. E-mail: renatapgama@gmail.com | (1) ORCID
\end{abstract}

Resumo: Este artigo apresenta uma pesquisa sobre a atuação da equipe gestora que pode favorecer o bom desempenho em Matemática nos anos iniciais do ensino fundamental. A metodologia utilizada se constituiu de cunho qualitativo e interpretativo. A análise teórica fundamentou-se nos conceitos de organização escolar, gestão democrática e eficácia da escola e utilizou a técnica de triangulação dos dados com um corpus de análise constituído a partir de questionário misto e entrevista semiestruturada com as equipes gestoras e documentos oficiais sobre as escolas e sobre os gestores. A pesquisa foi desenvolvida em seis escolas de uma rede municipal de ensino que apresentaram notas crescentes em matemática e IDEB em ascensão nas edições da Prova Brasil de 2011, 2013 e 2015. Os resultados evidenciaram que as equipes gestoras pesquisadas desenvolvem intencionalmente, ações voltadas ao ensino da matemática, tais como atribuição de aulas de turmas de $4^{\circ}$ e $5^{\circ}$ anos aos docentes com maiores afinidades em matemática, formação continuada, planejamento e replanejamento de atividades pedagógicas, estímulo à comunicação organizacional clara e aos trabalhos colaborativos.

Palavras-chave: Equipe gestora. Ensino da matemática. Prova Brasil.

Abstract: This article presents a research on the performance of the management team that can favor the good performance in mathematics in the early years of elementary school. The methodology used consisted of a qualitative and interpretative nature. The theoretical analysis was based on the concepts of school organization, democratic management and school effectiveness using the data triangulation technique with a corpus of analysis constituted from a mixed questionnaire and semi-structured interview with the management teams and official documents about the schools and about managers. The research was developed in six schools of a municipal education network that presented increasing notes in mathematics and IDEB on the rise in the editions of the Brazil Test of 2011, 2013 and 2015. The results showed that the researched management teams intentionally develop, actions directed to the teaching of mathematics, such as the assignment of classes of grades of 4 and 5 years to professors with higher affinities in mathematics, continuing education, planning and replanning of pedagogical activities, encouraging clear organizational communication and collaborative work.

Keywords: Management team. Teaching mathematics. Brazil test.

- Recebido em 06 de fevereiro de 2019 • Aprovado em 14 de agosto de 2019 • e-ISSN: 2177-5796

DOI: http://dx.doi.org/10.22483/2177-5796.2020v22n1p225-248

Copyright @ 2019. Conteúdo de acesso aberto, distribuído sob os termos da Licença Internaonal da CreativeCommons - CC BY-NC-SA Atribuição Não Comercial (https://br.creativecommons.org/licencas/) - Permite distribuição e reprodução, desde que atribuam os devido créditos à publicação, ao autor(es) e que licenciem as novas criações sob termos idênticos. 
Resumen: Este artículo presenta una investigación sobre el desempeño del equipo directivo que puede favorecer el buen desempeño en Matemáticas en los primeros años de la escuela primaria. La metodología utilizada fue de naturaleza cualitativa e interpretativa. El análisis teórico se basó en los conceptos de organización escolar, gestión democrática y efectividad escolar y utilizó la técnica de triangulación de datos con un corpus de análisis constituido por un cuestionario mixto y una entrevista semiestructurada con los equipos de gestión y documentos oficiales sobre las escuelas. y sobre gerentes. La investigación se llevó a cabo en seis escuelas en un sistema escolar municipal que tuvo calificaciones crecientes en matemáticas e IDEB en las ediciones de Prova Brasil en 2011, 2013 y 2015. Los resultados mostraron que los equipos gerenciales encuestados desarrollaron intencionalmente acciones dirigidas a la enseñanza de matemáticas, como la asignación de clases de 4to y 5to año a maestros con mayor afinidad en matemáticas, educación continua, planificación y re-planificación de actividades pedagógicas, fomentando una comunicación organizacional clara y trabajo colaborativo.

Palabras clave: Equipo directivo. Enseñanza de las matemáticas. Degustación de Brasil. 


\section{Introdução}

Esse artigo apresenta resultados de uma investigação sobre a atuação da equipe gestora frente ao ensino da matemática. O objetivo se constituiu em identificar, descrever e compreender as ações da equipe gestora que podem favorecer o bom desempenho em Matemática nos anos iniciais do ensino fundamental.

O estudo aqui apresentado é fruto da vivência como professor de matemática e como gestor da escola pública, tendo ocupado cargos de vice-diretor e atualmente desempenhando a função de supervisor de ensino em uma rede municipal. A pesquisa, vinculada ao Programa de Pós-Graduação, Mestrado em Educação, da Universidade Federal de São Carlos câmpus Sorocaba, teve seu início com a participação em um grupo de estudos da mesma universidade, chamado Grupo de Estudos e Pesquisa sobre Práticas Formativas e Educativas em Matemática (GEPRAEM), onde, por meio de leituras, debates e reflexões foi possível delinear os contornos da investigação.

A pesquisa foi desenvolvida em seis escolas de uma rede municipal de ensino do estado de São Paulo. Para a primeira etapa, as escolas foram selecionadas a partir de dois critérios, que são: 1. Desempenho das escolas municipais em três edições da Prova Brasil, nos anos de 2011, 2013 e 2015 buscando uma situação que configurasse notas crescentes em Matemática e 2. Índice de Desenvolvimento da Educação Básica (IDEB) crescente e acima das projeções estabelecidas pelo MEC na edição de 2015. O quadro 1 traz as seis escolas pré-selecionadas, a partir dos critérios descritos.

Quadro 1 - Notas da Prova Brasil em Matemática, IDEB e projeções

\begin{tabular}{|c|c|c|c|c|c|c|c|c|c|}
\hline \multirow[t]{3}{*}{ Escola } & $\begin{array}{c}\text { Nota } \\
\text { Prova } \\
\text { Brasil - } \\
2011\end{array}$ & $\begin{array}{c}\text { Nota } \\
\text { Prova } \\
\text { Brasil - } \\
2013\end{array}$ & $\begin{array}{c}\text { Nota } \\
\text { Prova } \\
\text { Brasil - } \\
2015\end{array}$ & IDEB & IDEB & IDEB & \multirow{2}{*}{\multicolumn{3}{|c|}{ Projeções }} \\
\hline & \multirow{2}{*}{ Matemática } & \multirow{2}{*}{ Matemática } & \multirow{2}{*}{ Matemática } & 2011 & 2013 & 2015 & & & \\
\hline & & & & $(\mathrm{N} \times \mathrm{P})$ & $(\mathrm{N} \times \mathrm{P})$ & $(\mathrm{N} \times \mathrm{P})$ & 2011 & 2013 & 2015 \\
\hline 1 & 219,10 & 222,98 & 237,72 & 5,5 & 5,8 & 6,4 & 5,7 & 6 & 6,2 \\
\hline 2 & 237,46 & 242,84 & 244,02 & 6,3 & 6,5 & 6,8 & 5,9 & 6,2 & 6,4 \\
\hline 3 & 230,03 & 234,54 & 237,16 & 6,1 & 6,2 & 6,4 & 5,1 & 5,4 & 5,6 \\
\hline 4 & 228,23 & 233,42 & 248,81 & 6,0 & 6,3 & 6,9 & 5,9 & 6,2 & 6,4 \\
\hline 5 & 239,33 & 242,53 & 250,93 & 6,4 & 6,6 & 7,0 & 6,3 & 6,5 & 6,8 \\
\hline 6 & 214,02 & 222,00 & 231,45 & 5,4 & 5,9 & 6,3 & 5,4 & 5,7 & 5,9 \\
\hline
\end{tabular}

Fonte: Elaborado pelo pesquisador. 
Para a segunda etapa da pesquisa, como as seis escolas, por meio de suas equipes gestoras, demonstraram ter ações voltadas ao ensino da matemática, foi utilizado um outro critério que buscou, entre as escolas participantes, aquelas que tivessem o maior e o menor percentuais de aprendizado adequado em matemática, conforme o INEP ${ }^{1}$. Nesse sentido, foram selecionadas a escola 4 com $71 \%$ de alunos que atingiram o aprendizado considerado adequado e a escola 6 com 52\%. Vale salientar que, de acordo com o INEP, os níveis vão de 0 a 10 e no portal Qedu, da Fundação Lemann e Meritt (2012), estes níveis de aprendizado aparecem agrupados conforme as denominações: insuficiente, básico, proficiente e avançado, sendo que aprendizado adequado equivale à soma das duas últimas. O quadro 2 apresenta as escolas e seus níveis de aprendizado adequado em matemática no ano de 2015.

Quadro 2 - Níveis de aprendizado adequado em matemática por escola.

\begin{tabular}{|c|c|c|c|c|}
\hline \multirow{2}{*}{ Escolas } & \multicolumn{4}{|c|}{ Níveis de aprendizado (\%) } \\
\cline { 2 - 5 } & $\begin{array}{c}\text { Insuficiente } \\
\text { (Níveis 0 a 2) }\end{array}$ & $\begin{array}{c}\text { Básico } \\
\text { (Níveis 3 e 4) }\end{array}$ & $\begin{array}{c}\text { Proficiente } \\
\text { (Níveis 5 e 6) }\end{array}$ & $\begin{array}{c}\text { Avançado } \\
\text { (Níveis 7 a 10) }\end{array}$ \\
\hline $\mathbf{1}$ & 7,64 & 29,63 & 41,46 & 21,27 \\
\hline $\mathbf{2}$ & 3,99 & 28,8 & 43,83 & 23,38 \\
\hline $\mathbf{3}$ & 4,89 & 31,21 & 47,78 & 16,12 \\
\hline $\mathbf{4}$ & 8,54 & 19,5 & 41,49 & 30,47 \\
\hline $\mathbf{5}$ & 3,93 & 30,99 & 33,39 & 31,69 \\
\hline $\mathbf{6}$ & 19,48 & 28,9 & 28,59 & 23,03 \\
\hline
\end{tabular}

Nota: Elaborado pelo pesquisador a partir dos dados do INEP/Qedu

Fonte: FUNDAÇÃO LEMANN e MERITT. Portal QEdu.org.br. Brasília: QEdu, 2012. Disponível em: http://www.qedu.org.br/. Acesso em: 19 nov. 2018.

Neste artigo, será apresentada uma das questões aplicadas no questionário que foi entregue aos gestores pesquisados, analisada primeiramente por entrecruzamento com a base teórica e em seguida com o aprofundamento por meio da triangulação dos dados obtidos nos questionários, na entrevista com as equipes gestoras e nos documentos oficiais que normatizam a gestão escolar no município.

\footnotetext{
${ }^{1}$ INEP: Instituto Nacional de Estudos e Pesquisas Educacionais Anísio Teixeira.
} 


\section{Atribuições das equipes gestoras}

As equipes gestoras das escolas pesquisadas possuem o diretor de escola, vice-diretor e orientador pedagógico nas escolas de ensino fundamental. Estes cargos fazem parte da classe de suporte pedagógico dentro do quadro do magistério, conforme lei municipal que disciplina o plano de carreira da educação. Nesse trabalho, os autores Libâneo (2004), Lück (2009) e Nóvoa (1995) deram embasamento teórico aos conceitos de organização escolar, gestão democrática e eficácia da escola.

Organização escolar, para Libâneo (2004), é comumente identificada como administração escolar. Os gestores têm a incumbência de planejar o trabalho da escola, racionalizando o uso de recursos materiais, financeiros e humanos, bem como coordenar e controlar o trabalho das pessoas.

A gestão democrática pressupõe a mobilização das pessoas para atuação coletiva em busca de objetivos educacionais comuns. Envolve a gestão compartilhada das ações com a participação de grupos colegiados como por exemplo o conselho de escola e a Associação de Pais e Mestres (APM). A participação efetiva dos vários segmentos da comunidade escolar, preconizada na Constituição Federal e na LDB (Lei nº 9394/96), é, sem dúvida, o caminho mais promissor para a busca de uma educação que vise uma sociedade mais justa e igualitária. Entretanto, há pela frente muitos desafios, como nos chama a atenção Dourado (1998)

[...] convivemos com um leque amplo de interpretações e formulações reveladoras de distintas concepções acerca da natureza política e social da gestão democrática e dos processos de racionalização e participação, indo desde posturas de controle social (qualidade total) até perspectivas de participação efetiva, isto é participação cidadã (p. 79).

Desse modo, podemos entender que apesar de todas as dificuldades, o gestor escolar precisa investir numa prática de gestão que envolva sempre as pessoas que mais se utilizam do espaço da escola, que são os alunos, pais, professores, funcionários, fornecedores e o entorno onde a instituição está localizada.

A gestão escolar democrática visa ao princípio maior da educação, que é formar pessoas que possam atuar coletivamente na sociedade, de forma a deixá-la melhor para as próximas gerações. Apesar das políticas públicas serem incipientes no quesito da universalização dos direitos a toda a população, em âmbito escolar, os gestores precisam buscar um ensino de 
qualidade, que seja direcionado a uma aprendizagem significativa e na linha da formação integral (FERREIRA, 2000).

Neste sentido, Lück (2009) defende que cabe aos gestores escolares, "criar cultura de valorização das capacidades, realizações e competências das pessoas pela celebração dos seus resultados, como um valor coletivo da escola e da educação" (p. 72).

Nóvoa (1995) destaca a existência de uma escola eficaz, quando esta possui, entre outras características de gestão, liderança organizacional, articulação curricular, autonomia, formação da equipe e participação dos pais. Concordo com o autor, entretanto, quando ele afirma que é bastante difícil isolar a variável gestão no estudo das organizações escolares, ampliando o entendimento para a cultura da escola como sendo uma área de investigação que permite mobilizar melhor estes conceitos.

$\mathrm{Na}$ equipe gestora considerada, todos os profissionais da educação são regidos por lei municipal que inclui a súmula de atribuições, ou seja, as atividades básicas que cada um deve realizar. Nessa perspectiva, o diretor escolar se destaca como responsável pelo encaminhamento do modo de ser e de agir da escola, bem como dos seus resultados. Os demais componentes dessa equipe (vice-diretor e orientador pedagógico) atuam em conjunto com o diretor, visando os mesmos objetivos que são de formar e manter uma organização com princípios ligados à liderança, ao planejamento, à orientação, à mediação, à coordenação, ao monitoramento e à avaliação dos processos educacionais necessários à promoção do ensino e da aprendizagem com qualidade social.

A escola, como local de formação de homens e mulheres, precisa estar preparada para este desafio que é de apresentar a cultura aos estudantes e inseri-los completamente na sociedade. Mas não somente a inserção, mas participação nas decisões importantes para a vida social, de cunho político-cultural, como currículo e ofertas de cursos na unidade e não somente decidir sobre "festas" e eventos na escola.

Nessa direção, os gestores têm um desafio à sua frente, que é, numa perspectiva democrática, transformar a escola num local onde o aluno possa ter a formação que o credencie para ser sujeito histórico, culturalmente inserido e que atue coletivamente. A educação que qualifica o homem como ser individual e prepara-o para a submissão à produção capitalista, leva 
ao acirramento da competitividade, condição que é contrária à igualdade de direitos e de oportunidades (BRASIL, 2006).

Nóvoa nos chama a atenção, neste mesmo sentido, quando se refere às escolas como

Instituições de um tipo muito particular, que não podem ser pensadas como uma qualquer fábrica ou oficina: a educação não tolera a simplificação do humano (das suas experiências, relações e valores), que a cultura da racionalidade empresarial sempre transporta (1995, p. 16).

Nesse contexto, pode-se inferir, portanto, que a gestão escolar nas escolas pesquisadas, engloba, de forma associada, o trabalho da direção escolar (diretor e vice-diretor) e da orientação pedagógica, como constituintes da equipe gestora da escola. Conforme o princípio da gestão democrática, a organização do processo de gestão abrange também a participação ativa dos docentes e da comunidade escolar como um todo, de modo a contribuírem para a concretização da busca pela qualidade de ensino para todos os estudantes (LÜCK, 2009).

Nas escolas, o trabalho da equipe gestora acaba se complementando, conforme as atribuições de cada um. Assim, enquanto a direção escolar organiza e prepara a escola para um evento, o orientador pedagógico pode dedicar seu tempo para a formação dos professores e atendimento aos alunos. O diretor é o profissional que lidera todo o trabalho educacional, mas que compartilha essa liderança com os outros profissionais da equipe gestora, com os docentes e com a comunidade escolar. Para Libâneo (2004), o diretor

Coordena, mobiliza, motiva, lidera, delega as responsabilidades decorrentes das decisões aos membros da equipe escolar conforme suas atribuições específicas, presta contas e submete à avaliação da equipe o desenvolvimento das decisões tomadas coletivamente. Nesse princípio, estão presentes a exigência da participação de professores, pais, alunos, funcionários e outros representantes da comunidade [...] (p. 143).

Os gestores escolares têm, assim, a função de articular as condições materiais e humanas no sentido de garantir o avanço dos processos sociais e educacionais que ocorrem na instituição de ensino. Para Lück (2009), a gestão escolar seria o meio e não o fim em si mesmo. O foco da gestão é a aprendizagem dos alunos, de forma significativa, ou seja, que faça sentido ao estudante.

No cotidiano da escola, espera-se que a comunidade discente desenvolva as competências que sejam úteis para a sociedade, de maneira criativa e contextualizada, expressando-se com 
clareza e utilizando os conceitos matemáticos para resolver problemas, bem como tomar decisões baseadas em fundamentos e solucionar conflitos.

Nesse contexto, dentro do rol de atribuições que a equipe gestora possui, esse trabalho busca especificamente, identificar e analisar as ações da equipe gestora que podem ter contribuindo para os bons resultados em matemática dos anos iniciais do ensino fundamental na Prova Brasil nas edições de 2011, 2013 e 2015.

\section{Metodologia da pesquisa}

A metodologia desenvolvida neste trabalho se constituiu de cunho qualitativo e interpretativo. Essa abordagem foi determinada pelo tipo de investigação a ser realizada, que envolve a identificação e compreensão das ações a partir das percepções dos próprios sujeitos. Citando Bogdan e Biklen (1982), Lüdke e André (1986, p. 12) afirmam que, "o significado que as pessoas dão às coisas e a sua vida são focos de atenção do pesquisador" e nos alerta sobre o cuidado com a precisão e interpretação dos dados.

Nesse sentido, foram selecionados como instrumentos para a construção dos dados, o questionário misto, a entrevista semiestruturada e os documentos que normatizam os cargos de gestão escolar no município, em especial as súmulas de atribuição. O questionário foi aplicado aos 18 participantes da pesquisa nas seis escolas selecionadas. Conforme Fiorentini e Lorenzato (2012), o questionário tem função de obtenção de informações e pode ser aplicado a um número grande de participantes. Neste artigo, os dados de uma das questões foram analisados de forma interpretativa, entrecruzados com a base teórica. A seguir foram consideradas para este trabalho, as entrevistas realizadas com as equipes gestoras de duas escolas selecionadas conforme o critério de maior e menor percentuais de aprendizado considerado adequado em matemática. Para Fiorentini e Lorenzato (2012, p. 120), a entrevista pode ser interessante porque faz surgir detalhes que não são "normalmente contemplados num simples questionário". Para análise e buscando o aprofundamento, foi realizada a triangulação dos dados obtidos com o questionário, com as entrevistas e com os documentos oficiais sobre a gestão escolar municipal, com base nos referenciais teóricos adotados neste trabalho. 
A técnica da triangulação foi a escolhida para a análise dos dados porque propicia uma comparação das informações obtidas por instrumentos diferentes. Conforme Denzin (1978) em Alves-Mazzotti e Gewandsznajder (2002), são quatro os tipos de triangulação: de fontes de dados (triangulação de dados), de métodos, de investigadores e de teorias. Nesse artigo, será realizada, portanto, a triangulação das fontes de dados a partir dos instrumentos escolhidos para coleta, visando obter informações mais precisas sobre o objeto pesquisado.

Dessa maneira, a investigação foi planejada de forma a levantar os dados do objeto de estudo, buscando-se, por meio dos instrumentos considerados, compreender a atuação das equipes gestoras com suas ações e percepções sobre o ensino da matemática nas unidades escolares que dirigem. Assim, a opção pela metodologia qualitativa deve-se, principalmente, à necessidade de compreender como os membros da equipe gestora atuam no dia a dia, desenvolvendo suas ações administrativas e pedagógicas que podem contribuir para o desempenho dos alunos em matemática.

As escolas foram identificadas com letras e números, bem como os gestores. Assim, foram usados para as escolas: E1, E2, E3, E4, E5 e E6. O diretor foi identificado pela letra D, seguido do número da escola, o vice-diretor foi identificado pelas letras VD, seguido do número da escola e o orientador pedagógico foi identificado pelas letras OP, seguido do número da escola. No sentido de conhecer os sujeitos da pesquisa, o quadro 3 mostra um perfil resumido dos gestores escolares participantes.

Quadro 3 - Experiência e situação funcional no cargo, dos gestores pesquisados.

\begin{tabular}{|c|c|c|c|c|}
\hline Escola & Cargo & Tempo no cargo & $\begin{array}{l}\text { Tempo de atuação } \\
\text { na escola }\end{array}$ & $\begin{array}{l}\text { Situação } \\
\text { funcional }\end{array}$ \\
\hline \multirow{3}{*}{1} & Diretor (D1) & 3 anos e 11 meses & 3 anos e 11 meses & Efetivo \\
\hline & Vice-Diretor (VD1) & 3 anos e 10 meses & 3 anos e 10 meses & Efetivo \\
\hline & Orientador pedagógico (OP1) & 3 anos & 3 anos & Designado \\
\hline \multirow{3}{*}{2} & Diretor (D2) & 5 anos & 4 anos & Efetivo \\
\hline & Vice-Diretor (VD2) & 9 meses & 9 meses & Designado \\
\hline & Orientador pedagógico $(\mathrm{OP}) 2$ & 9 anos & 9 meses & Efetivo \\
\hline \multirow[b]{2}{*}{3} & Diretor (D3) & 6 anos & 10 meses & Designado \\
\hline & Vice-Diretor (VD3) & 1,5 anos & 9 meses & Designado \\
\hline
\end{tabular}




\begin{tabular}{|c|c|c|c|c|}
\hline & Orientador pedagógico (OP3) & 10 meses & 10 meses & Designado \\
\hline \multirow{3}{*}{4} & Diretor (D4) & 6 anos e 6 meses & 3 anos e 7 meses & Efetivo \\
\hline & Vice-Diretor (VD4) & 3 anos & 2 anos & Designado \\
\hline & Orientador pedagógico (OP4) & 3 anos & 2 anos e 11 meses & Efetivo \\
\hline \multirow{3}{*}{5} & Diretor (D5) & 9 anos e 9 meses & 3 anos e 9 meses & Efetivo \\
\hline & Vice-Diretor (VD5) & 1 ano e 7 meses & 1 ano e 7 meses & Efetivo \\
\hline & Orientador pedagógico (OP5) & 6 anos e 3 meses & 4 anos & Efetivo \\
\hline \multirow{3}{*}{6} & Diretor (D6) & 9 anos e 6 meses & 6 anos & Efetivo \\
\hline & Vice-Diretor (VD6) & 5 anos & 4 anos & Efetivo \\
\hline & Orientador pedagógico (OP6) & 6 anos e 5 meses & 1 ano & Efetivo \\
\hline
\end{tabular}

Fonte: Elaborado pelo pesquisador

Por fim, o trabalho buscou uma observação qualificada e adequada dos diversos itens a serem investigados. A delimitação do objeto de estudo, com sua configuração espaço-temporal, pode tornar mais claro o foco e facilitar a captação dos aspectos do problema pelos instrumentos selecionados para coleta de dados.

\section{Ações das equipes gestoras direcionadas ao ensino da matemática}

A questão selecionada para este trabalho procurou identificar se cada gestor desenvolveu ações que podem ter contribuído para o bom rendimento em matemática e com quais ações cada um dos membros da equipe gestora poderia colaborar. Nesta perspectiva, apresentamos a seguir o panorama por escola e por cargo das respostas dadas pelos gestores, representadas pelas categorias "liderança", "pedagógica" e "monitoramento" com as respectivas subcategorias. Os valores apontados no quadro 4 são relativos ao número de ações realizadas por gestor em cada escola e a seguir, após um breve comentário, a análise está apresentada por categorias. 
Quadro 4- Ações voltadas à matemática, por escola e por cargo

\begin{tabular}{|c|c|c|c|c|c|}
\hline Escolas & Categoria & Subcategoria & D & VD & OP \\
\hline \multirow{5}{*}{$\begin{array}{c}\text { Escola } \\
1\end{array}$} & \multirow{3}{*}{ Liderança } & Apoio material & 0 & 1 & 0 \\
\hline & & $\begin{array}{l}\text { Compartilhamento e busca de novas } \\
\text { práticas }\end{array}$ & 0 & 0 & 1 \\
\hline & & Atribuição de turmas & 1 & 0 & 0 \\
\hline & \multirow{2}{*}{ Pedagógica } & Recursos didáticos & 0 & 1 & 1 \\
\hline & & Planejamento & 0 & 0 & 1 \\
\hline \multirow{5}{*}{$\begin{array}{c}\text { Escola } \\
2\end{array}$} & \multirow{3}{*}{ Liderança } & Apoio da gestão & 1 & 1 & 1 \\
\hline & & Apoio material & 1 & 0 & 0 \\
\hline & & Organização de horários & 1 & 0 & 0 \\
\hline & Pedagógica & Recursos didáticos & 1 & 0 & 0 \\
\hline & Monitoramento & Acompanhamento pedagógico & 1 & 0 & 0 \\
\hline \multirow{4}{*}{$\begin{array}{c}\text { Escola } \\
3\end{array}$} & \multirow[t]{4}{*}{ Liderança } & $\begin{array}{l}\text { Compartilhamento e busca de novas } \\
\text { práticas }\end{array}$ & 0 & 0 & 2 \\
\hline & & Formação contínua & 0 & 0 & 1 \\
\hline & & Comunicação & 1 & 0 & 0 \\
\hline & & Apoio da gestão & 0 & 1 & 1 \\
\hline \multirow{9}{*}{$\begin{array}{c}\text { Escola } \\
4\end{array}$} & \multirow[t]{6}{*}{ Liderança } & $\begin{array}{l}\text { Compartilhamento e busca de novas } \\
\text { práticas }\end{array}$ & 0 & 0 & 1 \\
\hline & & Formação contínua & 2 & 2 & 1 \\
\hline & & Comunicação & 1 & 0 & 0 \\
\hline & & Atribuição de turmas & 1 & 0 & 0 \\
\hline & & Organização de horários & 1 & 0 & 0 \\
\hline & & Apoio material & 1 & 1 & 0 \\
\hline & \multirow{2}{*}{ Pedagógica } & Recursos didáticos & 0 & 0 & 1 \\
\hline & & Planejamento & 1 & 0 & 0 \\
\hline & Monitoramento & Acompanhamento pedagógico & 1 & 0 & 0 \\
\hline \multirow{4}{*}{$\begin{array}{c}\text { Escola } \\
5\end{array}$} & \multirow[t]{4}{*}{ Liderança } & $\begin{array}{l}\text { Compartilhamento e busca de novas } \\
\text { práticas }\end{array}$ & 1 & 0 & 1 \\
\hline & & Apoio material & 1 & 1 & 0 \\
\hline & & Formação contínua & 1 & 1 & 3 \\
\hline & & Comunicação & 1 & 0 & 0 \\
\hline
\end{tabular}




\begin{tabular}{|c|c|c|c|c|c|}
\hline & & Apoio da gestão & 0 & 1 & 0 \\
\hline & Pedagógica & Recursos didáticos & 1 & 0 & 2 \\
\hline & Monitoramento & Acompanhamento pedagógico & 0 & 0 & 2 \\
\hline \multirow{6}{*}{$\begin{array}{c}\text { Escola } \\
6\end{array}$} & \multirow[t]{3}{*}{ Liderança } & $\begin{array}{l}\text { Compartilhamento e busca de novas } \\
\text { práticas }\end{array}$ & 1 & 0 & 0 \\
\hline & & Apoio material & 2 & 0 & 0 \\
\hline & & Apoio da gestão & 0 & 1 & 0 \\
\hline & \multirow{2}{*}{ Pedagógica } & Planejamento & 0 & 0 & 1 \\
\hline & & Recursos didáticos & 0 & 0 & 2 \\
\hline & Monitoramento & Acompanhamento pedagógico & 1 & 0 & 1 \\
\hline
\end{tabular}

Fonte: Elaborado pelo pesquisador.

O quadro 4 mostra as ações desenvolvidas na escola pela equipe gestora tendo em vista o desenvolvimento do ensino da matemática. Pode-se perceber que a categoria "liderança" apareceu nas seis escolas, a categoria "pedagógica" em cinco e "monitoramento" em quatro escolas. Assim, essas ações identificadas na pesquisa foram classificadas em categorias e subcategorias analíticas que serão detalhadas a seguir.

\section{Liderança}

Entre as ações do quadro 4, pondo a lupa na preocupação com a matemática, podemos notar que aquelas que se enquadram na categoria "liderança" foram citadas pela equipe gestora nas 6 escolas. A "atribuição de turmas", indicada por dois diretores, é ação por meio da qual, atribui-se as classes conforme o perfil do professor. Neste sentido, o D1 demonstra sua atenção com o ensino da matemática, quando aponta que "na atribuição docente, prioriza o perfil do professor, levando-se em consideração a experiência e sintonia da equipe da turma dos quintos anos”. O D4, por sua vez, relatou que a “atribuição das turmas segue a opção dos professores, porém com observação da equipe gestora quanto ao perfil pedagógico e potencialidades de cada profissional”. Assim, podemos inferir que, na percepção destes gestores responsáveis pela atribuição de turmas na escola, a matemática precisa ser ensinada por professores que tem mais afinidades com a matéria, principalmente nos quintos anos, conforme relata o D1. 
A entrevista com os gestores da escola 4 também trouxe esse dado. Para a orientadora pedagógica da escola, "os professores dos anos finais onde a matemática tem uma complexidade, são professores que gostam de matemática” (OP4, ENTREVISTA, 2018). Essa atitude encontra respaldo na Instrução SEDU/GS nº16/2017 (SOROCABA, 2017) ${ }^{2}$, em seu artigo $3^{\circ}$, que determina o que compete ao diretor de escola e na súmula de atribuições deste cargo, que é “cumprir e fazer cumprir as leis do ensino, as determinações das autoridades escolares [...]" (SOROCABA, 2007).

A categoria "liderança" traz também, como ação voltada ao ensino da matemática, a “organização de horários”, como na afirmação do D2 quando diz que

Alguns professores que utilizam algumas "brechas" em horários de aulas para desenvolverem junto aos alunos com dificuldades específicas (por exemplo: "divisão") atividades pedagógicas diferenciadas, o que também possibilita melhoria e avanço na aprendizagem. (D2, ENTREVISTA, 2018)

A diretora da escola 4, tendo em vista o estímulo ao ensino da matemática, também procura dinamizar a HTP para estudos entre os professores. Para ela a "organização das HTP coletivas preveem momentos para formação e para planejamento e replanejamento aos docentes".

$\mathrm{Na}$ entrevista da equipe gestora da escola 4, a diretora frisou que procura reunir os professores conforme a afinidade entre eles, ou seja, procura atender ao perfil de cada um. Assim, são formados grupos mais produtivos que podem planejar as atividades em conjunto para turmas semelhantes.

A organização escolar, no que se refere aos horários, é atribuição do diretor e o fato de apoiar aulas de reforço na unidade escolar pode potencializar a aprendizagem dos alunos, especialmente dos estudantes que apresentam maior dificuldade. A súmula de atribuições prevê que o diretor possa “providenciar a organização dos horários de trabalho [...]”. Para Lück (2009, p. 127), o diretor. visando a melhoria da qualidade do ensino, "promove o bom aproveitamento do tempo escolar em todas as ações escolares, orientando a sua organização nas aulas e no calendário escolar e o seu uso máximo na promoção da aprendizagem plena de todos os alunos".

\footnotetext{
${ }^{2}$ Instrução SEDU/GS no 16 de 22 de novembro de 2017, que dispõe sobre o processo de atribuição de turmas,
} classes e aulas aos docentes efetivos da rede municipal de ensino. 
A "comunicação" é outra subcategoria com ações que se destacaram para 3 diretores na categoria "liderança". Para eles é essencial manter o diálogo com a equipe e com os pais para que se avance na aprendizagem da matemática. A D3 por exemplo, mencionou que é adepta do "diálogo com os professores que sentem necessidade em buscar novas alternativas para a melhoria do desempenho de seus estudantes”.

A escola, como uma organização social, além de uma comunicação eficiente, deve possuir uma competente rede de relações interpessoais, o que de acordo com estudos atuais, é essencial para o desenvolvimento das pessoas presentes no ambiente (ANDRADE, 2003). Essa rede se forma com as ações e comportamentos das pessoas, por meio do que se escreve e do que se fala na escola. A clareza das informações que circulam na escola é essencial para manter a eficácia do processo educacional e por isso não é interessante permitir que a comunicação ocorra sem uma atenção especial de toda a equipe.

O "apoio da gestão", dentro da categoria "liderança", é importante para 1 diretor, 4 vicediretores e para 2 orientadores pedagógicos em 4 escolas. Estes profissionais sinalizam que o suporte oferecido aos professores e alunos é fundamental e pode contribuir ao ensino da matemática. O VD2 apontou que dá “apoio aos professores em seus projetos para avanço de todos os alunos", semelhante ao VD3 que provê "apoio enquanto suporte pedagógico para agilizar para que o trabalho aconteça com qualidade”.

O "apoio da gestão" pode ser comparado ao suporte que é dado ao processo de ensino e aprendizagem que está presente inclusive na denominação dos cargos que são objeto dessa pesquisa. Na administração municipal, conforme a Lei no 4.599/94, alterada pela Lei no 8.119/07, o magistério é classificado em suporte pedagógico e docente (SOROCABA, 2007).

A subcategoria "formação contínua" foi sinalizada por 3 diretores, 3 vice-diretores e 5 orientadores, como determinante para justificar o ensino de matemática nas escolas pesquisadas. Para o OP5, por exemplo, as conversas formais e informais com os professores foram importantes para o ensino e aprendizagem da matemática. O D4 e o D5 destacaram que participam de todas as reuniões de HTP coletivos com o intuito de colaborar com a formação contínua dos professores.

Pactuo com Libâneo (2004) quando ele escreve que 
O desenvolvimento profissional e a conquista da identidade profissional dependem de uma união entre os pedagogos especialistas e os professores, assumindo juntos a gestão do cotidiano da escola, articulando num todo o projeto pedagógico, o sistema de gestão, o processo de ensino e aprendizagem, a avaliação. Fazendo assim, ter-se-á uma organização preocupada com a formação continuada, com a discussão conjunta dos problemas da escola, discussão que é de natureza organizacional, mas principalmente pedagógica e didática (p. 41).

A entrevista mostrou que há também a preocupação em oferecer formações com especialistas da área de matemática para maior aprofundamento dos estudos. Nesse sentido, sempre que possível, as equipes gestoras promovem encontros formativos dos professores com profissionais da matemática, como o D6, que organizava reuniões para que um dos professores, graduado em matemática, fizesse as formações e a OP4 que consultava o grupo de professores, para saber

Sobre o que eles queriam estudar, sempre significativo, a gente traz nossa necessidade, mas em primeiro lugar sempre o que o grupo docente quer e quando o assunto é a matemática, por exemplo, estudamos para passar ao grupo, em alguns momentos a gente traz especialista aqui, com investimento próprio, uma vez por semestre (OP4, ENTREVISTA, 2018).

A diretora da escola 4 mencionou que as formações oferecidas pela Secretaria da Educação foram fundamentais para o desenvolvimento profissional dos docentes e gestores. Ponderou, ainda, que devem ser realizadas por profissionais preparados com conhecimento sobre o tema, no caso, a matemática. A formação que ocorreu alguns anos atrás na rede, conhecida como Mathema ${ }^{3}$, trouxe bastante contribuição aos participantes, pois aconteceu nos moldes referidos pela diretora, ou seja, com "quem estuda com mais profundidade o assunto e aliando a prática à teoria” (D4, ENTREVISTA, 2018).

Conforme suas palavras, o modelo de formação desse curso é utilizado atualmente na escola, “[...] nos últimos três anos, pelo menos uma vez por semestre, a gente dedica um estudo em matemática, não posso dizer aprofundado porque não sou especialista, mas damos prioridade a parte conceitual e prática da matemática [...]” (D4, ENTREVISTA, 2018).

Outro destaque obtido junto à equipe gestora da escola 4, durante a entrevista, foi em relação ao trabalho realizado junto aos professores, em que são convidados a refletir sobre o ensino da matemática. A OP4 mencionou sobre a metacognição em matemática, que não seria

3 Mathema: Formação realizada pela Secretaria da Educação com a educadora Katia S. Smole, em 2014, principalmente para os professores da escola em tempo integral e orientadores pedagógicos. 
propriamente um projeto, mas sim um estudo realizado pela equipe de professores com a intenção de maior aprofundamento em algumas teorias relacionadas aos parâmetros curriculares do MEC e autoras como Kamii e Smole, numa tentativa de entender como a criança pensa.

Em relação aos professores novos, a D4 afirmou que, todo começo de ano, realiza a integração dos professores novos, recepcionando-os com um material explicativo sobre as ações pedagógicas desenvolvidas pela equipe docente durante o ano. Segundo ela, é um manual que contém informações sobre o funcionamento dos recursos da escola. Apresenta a "organização escolar, como entendemos os espaços escolares... aqui na escola, além das salas de aulas, nós temos sala de leitura, quiosques, brinquedoteca, azulejo, parque, lousas digitais” (D4, ENTREVISTA, 2018).

O "compartilhamento e busca de novas de práticas", outra subcategoria, teve ações mencionadas por 2 diretores e 4 orientadores pedagógicos. Os OP 1, 3, 4 e 5 citaram experiências de trocas entre os pares e busca de novas práticas. O D6, por exemplo, destacou as "apresentações de ações dos professores que melhor desenvolveram essa área (uso dos kits de robótica), durante um período, para seus colegas, em HTP, inclusive com novas técnicas" como uma ação sua que pode ter contribuído com o ensino de matemática. Lück (2009) reforça que o diretor "Lidera a atuação integrada e cooperativa de todos os participantes da escola, na promoção de um ambiente educativo e de aprendizagem, orientado por elevadas expectativas, estabelecidas coletivamente e amplamente compartilhadas" (p. 69).

A entrevista mostrou que essa ação gestora de incentivar o compartilhamento de novas práticas com a atitude colaborativa dos professores é muito frequente na escola 4. A VD4, em relação aos docentes, comentou que

A gente percebe que para a colega de trabalho que não tinha um olhar para a matemática abre-se um leque enorme, e ela passa a participar mais, perguntando para as amigas e eu vejo essa prática que dá muito certo. (VD4, ENTREVISTA, 2018)

As atitudes colaborativas também foram contempladas nas falas das equipes gestoras. Para Fiorentini (2004), citado por Gama (2007), nos grupos de trabalho colaborativo a participação é voluntária, mas, mesmo ocorrendo como parte da jornada dos professores em HTP, o compromisso em compartilhar os saberes e as experiências parece estar presente, assim como questões relacionadas à afetividade, confiança e disponibilidade para ouvir críticas, conforme 
relatos dos gestores. Os gestores das duas escolas destacaram a importância da participação do grupo de docentes ao preparar e aplicar as atividades de formação desenvolvidas diretamente por eles. Na escola 4, a cada mês, segundo a diretora, um dos professores do grupo estuda, para socializar com os colegas de turmas semelhantes, novas propostas de atividades, de forma colaborativa. A diretora citou que, cada professor fica responsável "pelo planejamento e então ele faz o melhor que pode com coisas diferentes e que as outros podem contribuir também [...]”" (D4, ENTREVISTA, 2018). A diretora da escola 4 mencionou também que

Podem surgir dúvidas numa formação de matemática que a gente também não consiga responder, apesar de poder acontecer com especialista também... a gente sempre fala que não sabe responder, mas que vai pesquisar mais para responder ou acontece no próprio grupo, uma já responde e colabora...e ali se fecha o conceito (D4, ENTREVISTA, 2018).

Nesse sentido, a OP6 sublinhou que, em geral, todos os professores colaboram com o processo, preparando os planejamentos e atividades do período e trocando com os colegas durante as reuniões em HTP,

[...] situações que são bem avaliadas dentro da sala de aula...são atividades cotidianas que dão certo, a gente abre o espaço para o professor para que fale no HTP (olha, eu fiz isso e deu certo), se deu certo para um professor, pode ser que não dê para outro, mas o fato de você fazer essa troca, acho isso importante...outra coisa que a gente tem tentado sistematizar para ver como as coisas funcionam. (OP6, ENTREVISTA, 2018)

Nesse ponto, entendemos que, sendo de uma forma não imposta, pressupondo que cada professor deve ter sua individualidade respeitada, a contribuição de cada um do grupo pode "aumentar o conhecimento profissional pedagógico e a autonomia", conforme enfatiza Imbernón (2010, p. 64). A cultura da colaboração pode ser promovida pela equipe gestora, mas uma vez que se fortaleça na escola, pode fazer com que os próprios professores se tornem líderes do processo (FULLAN; HARGREAVES, 2000).

Na legislação, os documentos oficiais apontam que a equipe gestora é indicada para mediar as formações que ocorrem no interior das escolas. De acordo com o previsto na súmula de atribuições, o orientador pedagógico está incumbido da formação contínua dos professores, mas de uma forma geral, toda a equipe gestora participa, seja na organização ou até mesmo na condução do momento formativo.

A subcategoria "apoio material", ou seja, o provimento de condições materiais para o desenvolvimento do ensino da matemática foi citado por 4 diretores e por 3 vice-diretores, em 5 
escolas. Os VD 1, 4 e 5 responderam que dão apoio financeiro para o atendimento dos pedidos dos professores para os trabalhos pedagógicos em matemática. O D4 frisou que pode contribuir "dando apoio e suporte financeiro para a realização de projeto matemático que venha enriquecer o ensino aprendizagem”. Na entrevista, o diretor da escola 6 destacou que, pensando no ensino da matemática, "mobiliza a APM e o conselho de escola para as decisões sobre investimento das verbas da escola, como para ativação da sala de jogos, sala de leitura e de informática” (D6, ENTREVISTA, 2018). Ele afirmou que a escola foi bem equipada nos últimos anos com sistema de som, sala de leitura, sala de jogos e de informática, tudo conseguido, conforme o diretor, com apoio da comunidade. Em relação à aprendizagem dos alunos, no sentido de promover a exploração de atividades diversificadas em matemática, o D6 frisou que reserva, mensalmente, quantidade adequada de cópias de atividades, aos professores. Estas ações são respaldadas pela súmula de atribuições dos cargos de gestão, que prevê "administrar o pessoal, os recursos materiais e financeiros do estabelecimento de ensino" (SOROCABA, 2007).

Lück (2009) refere-se ao diretor da escola como um administrador dos recursos financeiros e materiais da unidade escolar, cujo emprego correto pode contribuir para os resultados de aprendizagem. Isso indica que, na percepção dos gestores investigados, o ensino da matemática pode ser melhorado com mais investimentos em recursos materiais.

\section{Pedagógica}

As ações categorizadas como "pedagógica" foram mencionadas por gestores de 5 escolas. Dentro da subcategoria "planejamento", as ações foram apontadas pelo D4, OP1 e OP6. Em "recursos didáticos", 2 diretores (D2 e D5), 1 vice-diretor (VD1) e 4 orientadores pedagógicos (OP1, OP4, OP5 e OP6) relataram ações realizadas que podem ter contribuído com o ensino da matemática. O OP6 por exemplo sinalizou que "indicação de materiais, jogos e leituras quando necessário" pode ser interessante para desenvolver o ensino da matemática. Os projetos são também mencionados pelos gestores pesquisados, levando a crer que na percepção deles, seu uso pode melhorar o ensino da matemática.

A entrevista com a equipe gestora da escola 6 mostrou que há um projeto que envolve o uso de moeda criada pelos próprios alunos para utilização durante eventos festivos na escola. Conforme o diretor, os alunos praticam a matemática, como 
Na semana das crianças em que temos uma série de atividades e aquela quadra lá embaixo, vira uma área de lazer...nessa semana eles tem diversas atividades, filmes escolhidos por eles, para assistir e eles compram os ingressos, com dinheiro fictício. (D6, ENTREVISTA, 2018)

Para ele, fica forte o "desenvolvimento da autonomia da criança, criança com seis anos de idade pagando, fazendo troco", porque “tem que controlar o dinheiro para não faltar” (D6, ENTREVISTA, 2018).

De fato, quando pensamos nas intermináveis listas de exercícios, que envolvem apenas o certo ou o errado para o aluno, nos projetos, o estudante pode encontrar um ambiente de descobertas. Skovsmose (2008), citado por Nacarato, Mengali e Passos (2016), chama atenção de que o ponto de partida não é a lista de exercícios:

[...] as explorações acontecem por meio de um "roteiro de aprendizagem" no qual os alunos têm a oportunidade de apontar direções, formular questões, pedir ajuda, tomar decisões, etc. Vale salientar que são os alunos que percorrem o cenário de aprendizagem, e não o professor ou os autores do livro-texto que costumam preestabelecer uma trajetória na forma de exercícios que não deixa tempo ou opções para rotas alternativas (SKOVSMOSE, 2008, p. 64 apud NACARATO; MENGALI; PASSOS, 2016, p. 22).

Essa forma de interpretar o ensino da matemática sugere que a aprendizagem não se dá com memorização e repetição, mas sim como uma prática social que leva o aluno a se envolver com uma tarefa significativa. Conforme Nacarato, Mengali e Passos (2016), aprender é um processo gradativo que necessita de relações. A cada momento vivido é possível produzir novos significados e o pensamento matemático vai sendo qualificado.

\section{Monitoramento}

O "acompanhamento pedagógico" envolveu ações dentro da categoria "monitoramento" e foi apontado por 3 diretores e 2 orientadores pedagógicos pesquisados em 4 escolas. Na busca por uma educação de qualidade, a ação de acompanhamento pedagógico é atividade inerente à gestão escolar, isto é, feita regularmente visa determinar se o que foi planejado está sendo cumprido. O D2 afirmou faz o “acompanhamento da aprendizagem” ao passo que o D6 acompanha os resultados de matemática nas avaliações externas e internas. O OP 5 frisou que é importante para o ensino da matemática "acompanhar as atividades, através do semanário (planejamento semanal)" e o OP 6 relata que faz “análise de sondagens". Aqui, Lück (2013) nos ajuda quando defende que o orientador pedagógico busca a melhoria dos processos de 
desempenho do professor e de avaliação dos alunos. A autora reforça que "a observação e feedback" são, portanto, fundamentais para promover o desenvolvimento profissional dos professores. Em obra de 2009, na página 43, a autora Lück menciona que o diretor pode se servir dos resultados para "a tomada de decisões, para o planejamento e organização do trabalho escolar com foco na melhoria da aprendizagem dos alunos".

$\mathrm{Na}$ entrevista, apareceu com grande destaque o acompanhamento do processo de ensino e aprendizagem, facilitado pelo planejamento conjunto, conforme a diretora da escola 4. Define com os docentes "o que precisa ser trabalhado, aluno por aluno, professora por professora, e o planejamento da sala que ela faz, um acompanhamento como um todo [...]” (D4, ENTREVISTA, 2018). Na escola 6, a orientadora pedagógica ressaltou que prioriza o planejamento bimestral, que, "desde o ano passado tem sido construído de acordo com as necessidades da escola, olhando para a documentação que é a matriz curricular" e a partir das sondagens que são feitas a cada período de avaliação.

Triangulando os dados do questionário e da entrevista com a súmula de atribuições é possível perceber que os profissionais envolvidos nessa pesquisa mostraram preocupação com a matemática em suas escolas, revelando fortes indícios de cumprimento às obrigações relacionadas ao processo de ensino e aprendizagem, como colaborar com o PPP, orientar pedagogicamente o educador e avaliar os resultados (SOROCABA, 2007).

Os resultados aqui apresentados mostram que as equipes gestoras realizam um trabalho intencional voltado ao ensino da matemática entre tantas outras atividades inerentes aos cargos de gestão escolar. O "apoio material" para os projetos, citado por gestores de cinco das seis escolas, indica que há investimentos em materiais e recursos didáticos para o desenvolvimento do ensino da matemática nas escolas. O "compartilhamento e busca de novas de práticas", outra subcategoria com ações mencionadas pelos gestores, mostrou que há o incentivo por parte destes às atitudes colaborativas entre os professores. Os dados revelaram também que as atividades desenvolvidas nas preparações das aulas e em planejamento e replanejamento são realizadas por todos os docentes.

A atribuição das turmas conforme o perfil do professor é outra ação realizada pela gestão escolar no sentido de aproveitar ao máximo as características de cada docente. Os professores dos 
anos finais onde a matemática apresenta uma maior complexidade, na opinião dos gestores, são aqueles que demonstram maiores afinidades com a matemática.

O monitoramento das ações realizadas, por meio do "acompanhamento pedagógico" foi mencionado pelos gestores na maioria das escolas, indicando que há um comprometimento das equipes gestoras em realizá-lo. Pedagogicamente é uma ação importante porque possibilita a tomada de decisão das equipes gestora e docente na busca da qualidade do processo de ensino e aprendizagem.

Em síntese, as equipes gestoras demonstraram que desenvolvem ações voltadas ao ensino da matemática enquanto líderes do processo educacional na escola. Indicaram que são presentes e atuantes pedagógica e administrativamente no sentido de manter e melhorar os resultados educacionais.

\section{Considerações finais}

As equipes gestoras das unidades escolares selecionadas a partir dos critérios utilizados, notas de matemática e IDEB crescentes nas edições da Prova Brasil de 2011, 2013 e 2015, demonstraram que dentre muitas tarefas que empreendem diariamente na escola, desenvolvem ações de gestão administrativa e pedagógica que podem contribuir para o ensino e aprendizagem da disciplina investigada.

Os dados apresentados indicam que há ações intencionais direcionadas à organização das escolas e preparação dos horários na Hora de Trabalho pedagógico (HTP), principal momento de formação dos professores que ensinam a matemática. Os gestores evidenciaram que se comprometem com ações e estratégias que proporcionam momentos de formação contínua e compartilhamento de experiências e de práticas entre os professores. Notamos que as equipes gestoras são bastante cuidadosas na organização e no planejamento e replanejamento dessas ações que podem ser desenvolvidas nos horários reservados para as atividades e que o fato de reunir a todos possibilita tratar de temas como o ensino da matemática, entre tantos outros. As equipes gestoras chamaram a atenção para estas ações de compartilhamento de práticas e de trabalho colaborativo ao descrever que os próprios professores preparam as atividades e as apresentam aos colegas durante as reuniões de HTP. Assim, incentivados pela gestão, os docentes 
demonstram atitudes colaborativas porque desenvolvem um trabalho coletivo em que se percebem como participantes que compartilham seus saberes e promovem reflexões entre os pares. Essa união dos professores em busca dos objetivos educacionais estabelecidos pode gerar oportunidades de desenvolvimento contínuo e de aprendizagem profissional na carreira. Os docentes precisam de horários para reflexão coletiva e o desenvolvimento curricular e o crescimento profissional do professor são influenciados por estes momentos.

O planejamento conjunto foi outra ação evidenciada neste estudo, é feito também com a participação ativa de cada um dos professores, que podem, durante o ano preparar atividades que serão aproveitadas por todos os docentes ou por aqueles que atendem turmas do mesmo ano. Nesse sentido, a equipe gestora pode, com suas ações intencionais, contribuir para organizar os espaços e para ouvir o que dizem professores e alunos (ESPINOSA; FIORENTINI, 2005, p. 172).

Assim, o ensino da matemática praticado na escola que pode ter influenciado os resultados das avaliações externas (Prova Brasil), na percepção dos gestores, deveu-se principalmente às ações voltadas à liderança, as de natureza pedagógica e ao monitoramento dessas ações. As equipes gestoras demonstraram que realizam o monitoramento do processo de ensino e aprendizagem sistematicamente, com acompanhamento e orientação para elaboração dos semanários e também atuam na revisão das atividades de sondagens a serem aplicadas aos alunos. Estas, realizadas bimestralmente, são momentos em que os gestores aproveitam para dialogar com os docentes sobre o desempenho dos alunos e sugerem mudanças. O acompanhamento dos processos educacionais desenvolvidos pode ser de grande relevância se for utilizado para tomada de decisão no sentido de melhorar os processos educacionais na escola.

Os gestores mostraram capacidade de comunicação e procuraram apoiar os professores em seus projetos, em especial aos ligados à matemática. A habilidade em praticar uma comunicação clara dos objetivos educacionais a serem alcançados dentro da escola demonstra um aspecto destacado dos gestores como lideranças efetivas. O projeto pedagógico da escola envolve a todos em sua construção, execução e avaliação e por isso, as análises conjuntas são essenciais para identificar processos que podem ser mantidos e melhorados continuamente ou mesmo aqueles que devem ser abandonados pelo grupo. As entrevistas realizadas com as equipes gestoras de duas escolas serviram para confirmar que o alinhamento do diálogo interno à 
organização pode trazer benefícios ao processo de ensino e aprendizagem, uma vez que busca a integração da equipe em torno dos mesmos ideais de educação. Assim, entendemos que o diálogo pode também contribuir com o desenvolvimento da equipe escolar e dessa forma, tornar a escola uma organização que aprende e que está aberta à inovação. Verifica-se, aqui, que o desempenho profissional da equipe gestora pode ser um fator a ser considerado na qualidade do ensino da matemática.

Nóvoa (1995) defende que a eficácia das escolas passa pela implementação de programas de formação continuada e profissional de quem trabalha na instituição de ensino, especialmente dos docentes. Ele reforça que essa formação deve estar articulada com o projeto pedagógico da escola e com a prática de trabalhos de investigação-ação que melhorem efetivamente a qualidade da educação nas escolas. As ações de articulação internas à escola podem ser mais bem direcionadas quando a equipe gestora se propõe a organizar o espaço escolar de modo a favorecer o encontro dos professores para o desenvolvimento de um trabalho colaborativo visando a melhoria do processo de ensino e aprendizagem.

\section{Referências}

\section{ALVES-MAZZOTTI, A. J.; GEWANDSZNAJDER, F. O método das ciências sociais, pesquisa quantitativa e qualitativa. São Paulo: Pioneira, 2002.}

ANDRADE, Rosa Maria Calaes de (org.). O cotidiano educacional. Porto Alegre: Artmed, 2003. BRASIL. MINISTÉRIO DA EDUCAÇÃO. SECRETARIA DE EDUCAÇÃO BÁSICA. Gestão da educação escolar. Brasília: Universidade de Brasília, Centro de Educação a Distância, 2006.

DOURADO, L. F. A escolha de dirigentes escolares : política e gestão da educação no Brasil. In: FERREIRA, N. S. C. (Org.). Gestão democrática da Educação : atuais tendências, novos desafios. São Paulo : Cortez, 1998

ESPINOSA A. J.; FIORENTINI, D. (Re)significação e reciprocidade de saberes e práticas no encontro de professores de matemática da escola e da universidade. In: FIORENTINI, D. A.; NACARATO, A. M. (org.). Cultura, formação e desenvolvimento profissional de professores que ensinam matemática: investigando e teorizando a partir de prática. São Paulo: Musa, 2005, p. 152-174.

FIORENTINI, D.; LORENZATO, S. Investigação em educação matemática: percursos teóricos e metodológicos. Campinas: Autores Associados, 2012.

FERREIRA, N.S.C. Gestão democrática da educação para uma formação humana: conceitos e possibilidades. Em Aberto. Gestão escolar e formação de gestores. Brasília: Instituto Nacional de Estudos e Pesquisas Educacionais, v. 17, n. 72, jun. 2000. 
FUNDAÇÃO LEMANN e MERITT. Portal QEdu.org.br. Brasília: QEdu, 2012. Disponível em: http://www.qedu.org.br/. Acesso em: 19 nov. 2018.

FULLAN, M; HARGREAVES, A. A escola como organização aprendente: buscando uma educação de qualidade. Porto Alegre: Artes Médicas, 2000.

GAMA, Renata P. Desenvolvimento profissional com apoio de grupos colaborativos: o caso de professores de matemática em início de carreira. 2007. 240p. Tese (Doutorado em Educação: Educação Matemática) - Universidade Estadual de Campinas, Campinas, 2007.

IMBERNÓN, F. Formação continuada de professores. Porto Alegre: Artmed, 2010.

LIBÂNEO, J. C. Organização e gestão da escola: teoria e prática. São Paulo: Heccus, 2004.

LÜCK, H. Avaliação e monitoramento do trabalho educacional. Petrópolis: Vozes, 2013.

LÜCK, H. Dimensões da gestão escolar e suas competências. Curitiba: Editora Positivo, 2009.

LÜDKE, M.; ANDRÉ, M. E. D. A. Pesquisa em educação: abordagens educativas. São Paulo: E.P.U., 1986.

NACARATO, A. M.; MENGALI, B. L. S.; PASSOS, C. L. B. A matemática nos anos iniciais do ensino fundamental: tecendo fios do ensinar e do aprender. 2. ed. Belo Horizonte: Autêntica, 2016.

NÓVOA, A. Para uma análise das instituições escolares. In: NÓVOA, A. (coord.). As organizações escolares em análise. Lisboa: Publicações Dom Quixote: IIE, 1995. p. 13-43.

SOROCABA. Instrução SEDU/GS N 16, de 22 de novembro de 2017. Dispõe sobre o processo de atribuição de turmas, classes e aulas aos docentes efetivos, integrantes do Quadro do Magistério Público Municipal de Sorocaba, de acordo com os artigos 32 e 38, da Lei n ${ }^{\circ}$ 4599/1994 e alterações. Sorocaba: Secretaria da Educação, 2017. Disponível em: http://educacao.sorocaba.sp.gov.br/vida-funcional/wpcontent/uploads/sites/4/2017/02/instrucaon16atribaulascargasuplem.pdf. Acesso em: 14 dez. 2018.

SOROCABA. Lei no 8.119, de 29 de março de 2007. Dispõe sobre alteração de dispositivos da Lei ${ }^{\circ}$ 4.599, de 6 de setembro de 1994, que estabelece o Plano de carreira do quadro do magistério público municipal de Sorocaba e dá outras providências. Disponível em: https://leismunicipais.com.br/a/sp/s/sorocaba/lei-ordinaria/2007/812/8119/lei-ordinaria-n-8119-2007dispoe-sobre-alteracao-de-dispositivos-da-lei-n-4599-de-6-de-setembro-de-1994-que-estabelece-o-quadroe-o-plano-de-carreira-do-quadro-do-magisterio-publico-municipal-de-sorocaba-e-da-outrasprovidencias?q=8119. Acesso em: $14 \mathrm{dez} .2018$. 